\title{
IgM regulates airway hyperresponsiveness via modulation of actin associated genes.
}

SABELO HADEBE ( $\square$ hadebesabelo@yahoo.co.uk)

University of Cape Town https://orcid.org/0000-0002-6049-8395

Anca Flavia Savulescu

University of Cape Town

Jermaine Khumalo

LaJolla Institute

Katelyn Jones

University of Cape Town

Sandisiwe Mangali

University of Cape Town

Nontobeko Mthembu

University of Cape Town

Amkele Ngomti

University of Cape Town

Martyna Scibiorek

University of Cape Town

Javan Okendo

University of Cape Town https://orcid.org/0000-0001-8218-5448

Frank Brombacher

ICGEB

\section{Article}

Keywords: asthma, immunoglobulin M, T helper 2 cells

Posted Date: October 1st, 2021

DOI: https://doi.org/10.21203/rs.3.rs-891683/v1

License: @ (i) This work is licensed under a Creative Commons Attribution 4.0 International License.

Read Full License 
1 Running Title: IgM regulates airway hyperresponsiveness via modulation of actin

2 associated genes.

4 Authors and Affiliations:

5 Sabelo Hadebe ${ }^{1 *}$, Anca Flavia Savulescu ${ }^{2}$, Jermaine Khumalo ${ }^{1}$, Katelyn Jones ${ }^{1}$,

6 Sandisiwe Mangali ${ }^{1,3}$, Nontobeko Mthembu ${ }^{1}$, Amkele Ngomti ${ }^{1}$, Martyna Scibiorek ${ }^{1,3}$,

7 Javan Okendo ${ }^{2,5}$, Frank Brombacher ${ }^{1,3,4^{*}}$

8 'Division of Immunology, and South African Medical Research Council (SAMRC)

9 Immunology of Infectious Diseases, Department of Pathology, Faculty of Health

10 Sciences, University of Cape Town, Cape Town, South Africa

11 2Division of Chemical, Systems \& Synthetic Biology, Faculty of Health Sciences,

12 Institute of Infectious Disease \& Molecular Medicine, University of Cape Town, Cape

13 Town, South Africa

14 International Centre for Genetic Engineering and Biotechnology (ICGEB) and

15 Institute of Infectious Diseases and Molecular Medicine (IDM), Division of

16 Immunology, Health Science Faculty, University of Cape Town, Cape Town, South

17 Africa

${ }^{4}$ Wellcome Centre for Infectious Diseases Research in Africa (CIDRI-Africa), Institute

19 of Infectious Diseases and Molecular Medicine (IDM), Faculty of Health Sciences,

20 University of Cape Town, Cape Town, 7925, South Africa

$21{ }^{5}$ Centre for Research in Therapeutic Sciences (CREATES), Strathmore University,

22 Nairobi, Kenya 
* Corresponding Author: Professor Frank Brombacher

27 International Centre for Genetic Engineering and Biotechnology (ICGEB) and Institute 28 of

29 Infectious Diseases and Molecular Medicine (IDM), Division of Immunology, Health

30 Science

31 Faculty, University of Cape Town, Cape Town, South Africa

32 Email: brombacherfrank@gmail.com

33 Tel: +2721406 6424

34 Fax: +2721406 6938

35

36 * Corresponding author: Dr Sabelo Hadebe

37 Division of Immunology, Health Science Faculty, University of Cape Town, Cape

38 Town, South Africa

39 Email: sabelo.hadebe@uct.ac.za

$40 \quad$ Tel: +27214066161

$41 \quad$ Fax: + 27214066029

42

43 
44 Abstract: Allergic asthma is a disease driven by T helper 2 (Th2) cells, eosinophilia, airway hyperresponsiveness (AHR) and IgE-secreting B cells. Asthma is largely controlled by corticosteroids and $\beta_{2}$ adregenic receptor agonists that target and relax airway smooth muscle (ASM). Immunoglobulin M (IgM) isotype secreted by naïve B cells is important for class switching but may have other undefined functions. We investigated the role of IgM in a house dust mite (HDM)-induced Th2 allergic asthma model by sensitising wild type (WT) and $\lg M-d e f i c i e n t ~\left(\operatorname{lgM}^{-/-}\right)$mice with HDM. We validated our findings using CRISPR and single cell force cytometry in human ASM. We found IgM to be essential in AHR but not Th2 airway inflammation or eosinophilia. RNA sequencing of lung tissue suggested that IgM regulated AHR through modulating brain-specific angiogenesis inhibitor 1-associated protein 2-like protein 1 (Baiap2/1) and erythroid differentiation regulator 1 (Erdr1). Deletion of $B A I A P 2 L 1$ and ERDR1 reduced human ASM contraction when stimulated with TNF$\alpha$. These are unprecedented findings and have implications in future treatment of asthma beyond current therapies.

Summary: IgM regulates bronchoconstriction by interacting with BAIAP2L1 and $E R D R 1$ found in airway smooth muscle.

Main text: Immunoglobulin $M(\lg M)$ is the first antibody isotype expressed during $B$ cell development and the first humoral antibody responder, conserved across all species from zebrafish to humans (1). IgM can be divided into natural and antigeninduced IgM and can either be membrane bound IgM-type B cell receptor (BCR) or secreted $\lg M(2,3)$. Natural IgM plays multiple roles in homeostasis including scavenging and clearance of apoptotic cell debris in conjunction with phagocytic 
macrophages, B cell survival through tonic signals, lymphoid tissue architecture and prevention of autoimmune diseases (4-6). At mucosal sites, both natural and antigeninduced IgM play a role in shaping healthy microbiota and their repertoire, although limited, is also shaped by microbiota $(7,8)$. Secreted IgM antigen-complexes can connect signals via unique and shared receptors, suggestive of a more pleotropic role in homeostasis and disease states $(9,10)$.

Asthma is a T helper 2 (Th2) disease characterised by eosinophilic lung inflammation, mucus production, airway hyperresponsiveness (AHR), Th2 cytokines (interleukin-4 (IL-4), IL-5 and IL-13) and B cells producing IgE (11). IgM is central to class switch recombination that results in IgE class switched B cells. Currently, it is unclear whether natural or secreted IgM plays different roles compared to membrane bound IgM, which is more likely to undergo class switching to IgE. Here, we showed an unexpected function of secreted, and membrane bound IgM; namely, its involvement in modulating airway smooth muscle contraction. We sensitised and challenged IgM-deficient (IgM ${ }^{-}$ ${ }^{-}$) and wild type Balb/c (WT) mice with HDM intratracheally (i.t.) and analysed AHR, lung infiltrate and cytokines (Fig. 1, A, Fig. S1, A). We found moderately reduced resistance and elastance in $\operatorname{lgM}^{-/-}$sensitised with a high dose of $\mathrm{HDM}(100 \mu \mathrm{g})$ compared to WT mice (fig. S1, B). Similarly, we also observed profound reduction in AHR in $\operatorname{lgM}^{-/-}$mice sensitised with a low dose of HDM $(1 \mu \mathrm{g})$ compared to WT (Fig. 1, B). Interestingly, lung eosinophils were intact at both low dose (Fig. 1, C) and high dose HDM (fig. S1, C-D). We observed similar finding of profound AHR reduction in $\mathrm{IgM}^{-1-}$ mice in C57BL/6 background compared to WT mice (fig. S2, A). We also observed no significant changes between $\operatorname{lgM}^{---}$and WT mice in mucus production shown by Muc5a gene expression (Fig. 1, D) or goblet cells in C57BL/6 mice challenged with HDM (fig. S2, B). Accompanying reduction in AHR in $\operatorname{lgM}^{-1 /}$ mice was 
94 low titers of total IgE, HDM-specific IgE, and mediastinal lymph node (mLN) B cell surface expression of IgM and IgG1 (Fig. 1, E-F), owing to a lack of class switching. This was also consistent with what we found in $\mathrm{IgM}^{-/-}$mice in C57BL/6 background (fig. S2, C). Interestingly, the numbers of lung B cells were normal (Fig. 1, C) and the proportions of B cell subsets such as follicular, marginal zones and germinal centres (GCs) B cells were not affected by lack of IgM (Fig. 1, F), neither were CD4 T cells and $\mathrm{T}$ follicular helper cells (Fig. 2, A). This suggested a normal interaction between $B$ and T cells in GCs, but lack of AID-dependent class switching, despite increased expression of IgD (Fig. 2, D) (12). B1 cells develop in the yolk sac on embryonic day 9, before birth from a common lymphoid progenitor in the foetal liver and seed the peritoneal and pleural cavities (13-19). B1 cells are thought to be the main source of naturally occurring $\operatorname{lgM}$, although spleen and bone marrow (BM) cells can also contribute (20). We checked for natural IgM and antigen-induced IgM in multiple tissues in the absence of IgM. B cells expressing IgD were increased in all tissues including $\mathrm{mLNs}$, peritoneal cavity and spleen (fig. S3, A-C) and pre-B cell subsets were normal in BM (fig. S3, D) in the absence of IgM as previously reported (21). Lack of class switching is in contrast to earlier reports, which suggested that $\lg D$ can largely replace IgM for class switching to other isotypes, resulting in delayed neutralising IgG1 against vesicular stomatitis virus (VSV) $(21,22)$. We could also show that AHR reduction in $\mathrm{IgM}^{-/-}$mice was allergen-independent, as we observed similar findings using ovalbumin (OVA) complexed to alum adjuvant (fig. S4, A-B) and acute papaininduced allergic inflammation (fig. S4, C-D). To investigate whether reduction in AHR was due to reduced Th2 cells and cytokines, we stimulated total $\mathrm{mLN}$ and lung cells with anti-CD3 for 5 days or with PMA/ionomycin for 5 hrs in the presence of monensin and measured secreted or intracellular IL-4 and IL-13 expression. We found no 
differences in secreted or intracellular levels of these cytokines between $\operatorname{lgM}^{-/-}$and WT mice challenged with HDM (Fig. 2, B-C). To investigate what drives this reduced AHR in the absence of IgM between secreted antibodies or the cells, we transferred serum

122 from naïve WT mice into $\operatorname{lgM}^{-/-}$mice a day before sensitization with HDM allergen (Fig.

1232 , D) (23). AHR in lgM-/- was still reduced compared to WT mice even after transfer of

124 WT serum (Fig. 2, E), but levels of total IgE were increased and comparable to those 125 found in WT mice (Fig. 2, F). These findings verified previous studies which showed that IgM is abundant in mouse sera and reconstitution of IgM is difficult (3). We also tried to restore IgM function through adoptive reconstitution with congenic CD45.1 BM or sorted B cells into $\operatorname{lgM}^{-/-}$mice (fig. S5, A). This approach did not replenish IgM B cells to levels observed in WT mice and as a result did not restore AHR, total IgE and IgM in these mice (fig. S5, B-C). In order to understand why we could not reconstitute IgM, we checked for transferred congenic B cells in different organs after reconstitution with $\mathrm{BM}$ in $\mathrm{IgM}^{-/-}$mice and found some engraftment in $\mathrm{BM}$ and spleen, but poor engraftment to lung and $\mathrm{mLNs}$ which may explain our inability to restore AHR in $\mathrm{IgM}^{-}$ I- mice challenged with HDM (fig. S5, D). Because we had found no other changes in asthmatic allergic features between WT and $\operatorname{lgM}^{-/-}$, except for profound reduced AHR, we resorted to RNA sequencing to see if there were lung specific factors that influenced AHR regulation in IgM-deficient mice. Principal component analysis (PCA) clustered HDM-treated groups (PC1) separately from PBS control groups (PC2), 139 independent of mouse genotype (Fig. 3A). We found smaller variation in gene expression between WT and $\operatorname{lgM}^{-/-}$in both HDM challenged and PBS control mice (Fig. 3, B). We could mainly detect downregulation of genes such as brain-specific 142 angiogenesis inhibitor 1-associated protein 2-like protein 1 (Baiap2/1), erythroid 143 differentiation regulatory factor 1 (Erdr1), chemokines such as Cc/8, Cc/9, Ccl17 and 
$144 \mathrm{Ccl} 22$ in IgM $^{-/-}$mice challenged with HDM (Fig. 3, C-D). Interestingly, Baiap2/1 and

145 Erdr1 were also downregulated in $\operatorname{lgM}^{-/-}$saline-treated control mice, suggesting an

146 inflammation independent effect (Fig. 3, C, E). We also found presence of J-chain

147 coding gene in WT mice which was absent in $\mathrm{IgM}^{-/-}$mice, confirming a deletion in

148 genes associated with holding IgM monomers together and thus IgM (24) (Fig. 3, E).

149 Gene set enrichment analyses (GSEA) confirmed that the genes contributing to 150 changes in AHR between WT and $\operatorname{lgM}^{-/-}$were associated with muscle system

151 processes and skeletal muscle contraction (Fig. 3, F). There was also an over 152 representation of gene ratios associated with skeletal muscle development, 153 differentiation and contraction, and suppression of genes associated with chemotaxis 154 and plasma membrane bounded cell projection (fig. S6). We decided to focus on 155 Baiap2/1 (also known as IRTKS), which has been shown to promote actin polymerisation and microvilli length in the intestinal epithelial cells (25). We also focussed on Erdr1, a conserved factor in mice and humans, which has previously been shown to play a role in cancer through activation of natural killer cells via controlling 159 actin rearrangement (26). To understand how Baiap2/1 and Erdr1, genes 160 downregulated in IgM-deficient mice, could influence AHR, we resorted to an in vitro model that allowed us to measure contraction using fluorescently labelled elastomeric contractible surface (FLECS) technology (27) (Fig. 4, A). We chose human airway

163 bronchial smooth muscle cell (BSMCs) line as both BAIAP2L1 and ERDR1 are 164 expressed in structural cells including muscle and epithelial cells, and actin together 165 with myosin are essential in muscle contraction (28). To this end, we used CRISPR technology to knock down BAIAP2L1 and ERDR1 in BSMCs (fig. S7, A-B). BSMCs

167 (160 000/well) were stimulated with $10 \mu \mathrm{M}$ acetylcholine (ACh), $10 \mathrm{ng} / \mathrm{mL}$ of human 168 TNF- $\alpha$ and IL-13, followed by transfection with ribonucleoprotein (RNP) complexes 
containing single guide RNA targeting BAIAP2L1 and ERDR1 and Cas9 for 48h (Fig.

4, A). Transfected cells were seeded onto elastomeric patterns, stimulated with cytokines for $3 \mathrm{~h}$ and fixed in $4 \%$ paraformaldehyde, followed by staining with DAPI and Phalloidin before imaging on Stellarvision microscope and quantification (Fig. 4,

173 A). We validated deletion of BAIAP2L1 by PCR and showed deletion of BAIAP2L1 in ACh stimulated cells when compared to scramble sgRNA (fig. S7, C). Transfections with sgRNA did not impact cell viability (fig. S7, D). As expected, BSMCs displayed a higher level of contraction in TNF- $\alpha$ or IL-13 stimulated cells compared to unstimulated cells (Fig. 4, B-D). In BSMCs transfected with sgRNA-BAIAP2L1 and -ERDR1, we saw significant reduction in contraction levels in TNF- $\alpha$ stimulated cells when compared to scramble sgRNA transfected and stimulated cells (Fig. 4, B, C). We saw no differences in contraction between scramble sgRNA and sgRNA-BAIAP2L1 and -ERDR1 stimulated with IL-13 (Fig. 4, D). Taken together, this data indicates that BAIAP2L1 and ERDR1, two genes downregulated in IgM-deficient mice may have a role in inducing airway contraction of bronchial smooth muscle cells during asthma. Here, we described an unexpected function of $\lg M$ in regulation of bronchoconstriction. We show that in the lung tissue of IgM-deficient mice, there is reduction in genes associated with actin cytoskeleton, a key factor in smooth muscle contraction and AHR. We used single cell force cytometry to validate our findings in human ASM cell line and show as a proof of concept that deletion of BAIAP2L1 and ERDR1 reduced muscle contraction. The mechanisms of how $\lg \mathrm{M}$, also found at the interface of epithelial-mucosal surface, promotes diverse microbiota remains unclear. We believe these findings report for the first time an independent function of IgM from its natural class switching and non-specific binding to microbial components. We believe that IgM function in regulating ASM may be indirect through other unknown 
194 factors but does not involve microbiota as treatment of mice with mixture of antibiotics did not restore AHR (fig. S8A-B). Early vaccination with bacterial species, such as group $A$ streptococcus containing GlcNAc or $\beta-1,3-$ glucans can protect adult mice against $A$. fumigatus-induced allergic asthma (29). This is mainly through conserved germline-encoded IgM antibodies, which have broad specificities to common allergens containing GlcNAc moieties such as Dermatophytes $(8,30)$. We, therefore, speculate that in the absence of IgM in all its forms, such broad natural antibodies that recognise and react to environmental factors do not develop at an embryonic stage and therefore never learn to induce bronchoconstriction when seeing these factors at a later stage.

Acknowledgements. We thank $\mathrm{Dr}$ Hlumani Ndlovu for critically reading the manuscript. We thank the UCT Research Animal Facility for maintaining mice, Munadia Ansari for genotyping mice. We are grateful to Lizette Fick for excellent histology services and to confocal microscopy core facilities. We are grateful to Ronnie Dreyer for excellent cell sorting and Flow Cytometry Core Facility. We thank FlowJo for proving free service to Africa.

Funding: This work was supported by ICGEB, Cape Town Component, Medical Research Council (MRC) South Africa as well as support by the South African National

212 Research Foundation (NRF) Research Chair initiative (SARChi) to FB. SH is 213 supported by NRF Thuthuka Grant, South African MRC under a Self-initiated grant. 214 NM was supported by South African MRC PhD Fellowship. AN was supported by NRF MSc Scholarship.

216 Author contributions: Conceived and supervised study: SH FB. Performed the 217 experiments: SH AFS JK KJ NM MS AN. Analysed the data: SH AFS KJ JO NM. Wrote 
218 the paper: SH FB. All authors discussed the results and commented on the

219 manuscript.

220 Competing interests: The authors declare that they have no competing interests.

221 Data and materials availability: All data are available in the main text or the

222 supplementary materials and have not been deposited in public databases. RNA sequencing data is protected and will require materials transfer agreements (MTAs) until its protected by authors.

225

\section{REFERENCES:}

227 1. S. Akula, S. Mohammadamin, L. Hellman, Fc Receptors for Immunoglobulins and Their Appearance during Vertebrate Evolution. PLoS One. 9, e96903 (2014).

2. R. Blandino, N. Baumgarth, Secreted IgM: New tricks for an old molecule. J. Leukoc. Biol. 106, 1021-1034 (2019).

3. N. Baumgarth, O. C. Herman, G. C. Jager, L. E. Brown, L. A. Herzenberg, J. Chen, B-1 and B-2 Cell-Derived Immunoglobulin M Antibodies Are Nonredundant Components of the Protective Response to Influenza Virus Infection. J. Exp. Med. 192, 271-280 (2000).

4. M. R. Ehrenstein, C. A. Notley, The importance of natural IgM: scavenger, protector and regulator. Nat. Rev. Immunol. 10, 778-786 (2010).

5. E. Michaud, C. Mastrandrea, N. Rochereau, S. Paul, Human Secretory IgM: An Elusive Player in Mucosal Immunity. Trends Immunol. 41, 141-156 (2020).

6. P. Quartier, P. K. Potter, M. R. Ehrenstein, M. J. Walport, M. Botto, clearance of dying cells by murine bone marrow-derived macrophages in vitro. 
Eur. J. Immunol. 35, 252-260 (2005).

244 7. D. R. Wesemann, A. J. Portuguese, R. M. Meyers, M. P. Gallagher, K. CluffJones, J. M. Magee, R. A. Panchakshari, S. J. Rodig, T. B. Kepler, F. W. Alt, Microbial colonization influences early B-lineage development in the gut lamina propria. Nature. 501, 112-115 (2013).

8. J. S. New, B. L. P. Dizon, C. F. Fucile, A. F. Rosenberg, J. F. Kearney, R. G. King, Neonatal Exposure to Commensal-Bacteria-Derived Antigens Directs Polysaccharide-Specific B-1 B Cell Repertoire Development. Immunity. 53, 172-186.e6 (2020).

9. T. Kawahara, H. Ohdan, G. Zhao, Y.-G. Yang, M. Sykes, J. Immunol., in press, 253 doi:10.4049/jimmunol.171.10.5406.

254

255

10. T. T. T. Nguyen, B. A. Graf, T. D. Randall, N. Baumgarth, J. Immunol., in press, doi:10.4049/jimmunol.1700560.

11. B. N. Lambrecht, H. Hammad, The immunology of asthma. Nat. Immunol. 16, 45-56 (2014).

12. M. Muramatsu, K. Kinoshita, S. Fagarasan, S. Yamada, Y. Shinkai, T. Honjo, Class Switch Recombination and Hypermutation Require Activation-Induced Cytidine Deaminase (AID), a Potential RNA Editing Enzyme. Cell. 102, 553$563(2000)$.

13. K. Hayakawa, M. Asano, S. A. Shinton, M. Gui, D. Allman, C. L. Stewart, J. Silver, R. R. Hardy, Science (80-. )., in press, doi:10.1126/science.285.5424.113.

14. W. D. Hastings, S. M. Gurdak, J. R. Tumang, T. L. Rothstein, CD5+/Mac-1peritoneal B cells: A novel B cell subset that exhibits characteristics of B-1 cells. Immunol. Lett. 105, 90-96 (2006). 
15. E. Montecino-Rodriguez, H. Leathers, K. Dorshkind, Identification of a B-1 B cell-specified progenitor. Nat. Immunol. 7, 293-301 (2006).

16. E. Montecino-Rodriguez, K. Dorshkind, B-1 B Cell Development in the Fetus and Adult. Immunity. 36, 13-21 (2012).

17. M. Yoshimoto, E. Montecino-Rodriguez, M. J. Ferkowicz, P. Porayette, W. C. Shelley, S. J. Conway, K. Dorshkind, M. C. Yoder, Proc. Natl. Acad. Sci., in press, doi:10.1073/pnas.1015841108.

18. K. Hayakawa, R. R. Hardy, A. M. Stall, L. A. Herzenberg, L. A. Herzenberg, Immunoglobulin-bearing B cells reconstitute and maintain the murine Ly-1 B cell lineage. Eur. J. Immunol. 16, 1313-1316 (1986).

19. E. E. B. Ghosn, P. Sadate-Ngatchou, Y. Yang, L. A. Herzenberg, L. A. Herzenberg, Proc. Natl. Acad. Sci., in press, doi:10.1073/pnas.1019764108.

20. Y. S. Choi, J. A. Dieter, K. Rothaeusler, Z. Luo, N. Baumgarth, B-1 cells in the bone marrow are a significant source of natural IgM. Eur. J. Immunol. 42, 120129 (2012).

21. C. Lutz, B. Ledermann, M. H. Kosco-Vilbois, A. F. Ochsenbein, R. M. Zinkernagel, G. Kohler, F. Brombacher, IgD can largely substitute for loss of IgM function in B cells. Nature. 393, 797-801 (1998).

22. A. F. Ochsenbein, T. Fehr, C. Lutz, M. Suter, F. Brombacher, H. Hengartner, R. M. Zinkernagel, Science (80-. )., in press, doi:10.1126/science.286.5447.2156.

23. W. Wojciechowski, D. P. Harris, F. Sprague, B. Mousseau, M. Makris, K. Kusser, T. Honjo, K. Mohrs, M. Mohrs, T. Randall, F. E. Lund, CytokineProducing Effector B Cells Regulate Type 2 Immunity to H. polygyrus. Immunity. 30, 421-433 (2009). 
24. I. N. Norderhaug, F.-E. Johansen, P. Krajči, P. Brandtzaeg, Domain deletions in the human polymeric Ig receptor disclose differences between its dimeric IgA and pentameric IgM interaction. Eur. J. Immunol. 29, 3401-3409 (1999).

25. M. M. Postema, N. E. Grega-Larson, A. C. Neininger, M. J. Tyska, IRTKS (BAIAP2L1) Elongates Epithelial Microvilli Using EPS8-Dependent and Independent Mechanisms. Curr. Biol. 28, 2876-2888.e4 (2018).

26. Y. K. Houh, K. E. Kim, H. J. Park, D. Cho, Roles of erythroid differentiation regulator 1 (Erdr1) on inflammatory skin diseases. Int. J. Mol. Sci. 17, 1-10 (2016).

27. I. Pushkarsky, P. Tseng, D. Black, B. France, L. Warfe, C. J. Koziol-White, W. F. Jester, R. K. Trinh, J. Lin, P. O. Scumpia, S. L. Morrison, R. A. Panettieri, R. Damoiseaux, D. Di Carlo, Elastomeric sensor surfaces for high-Throughput single-cell force cytometry. Nat. Biomed. Eng. 2, 124-137 (2018).

28. H. Abo, B. Chassaing, A. Harusato, M. Quiros, J. C. Brazil, V. L. Ngo, E. Viennois, D. Merlin, A. T. Gewirtz, A. Nusrat, T. L. Denning, Erythroid differentiation regulator- 1 induced by microbiota in early life drives intestinal stem cell proliferation and regeneration. Nat. Commun. 11, 1-12 (2020).

29. N. W. Kin, E. K. Stefanov, B. L. P. Dizon, J. F. Kearney, J. Immunol., in press, doi:10.4049/jimmunol.1200702.

30. J. F. Kearney, P. Patel, E. K. Stefanov, R. G. King, Natural Antibody Repertoires: Development and Functional Role in Inhibiting Allergic Airway Disease. Annu. Rev. Immunol. 33, 475-504 (2015).

31. S. Hadebe, J. Khumalo, S. Mangali, N. Mthembu, H. Ndlovu, M. Scibiorek, A. Ngomti, F. Kirstein, F. Brombacher, Deletion of IL-4R\&\#x3b1; signaling on B cells limits hyperresponsiveness depending on antigen load. J. Allergy Clin. 
Immunol. 148, 99-109.e5 (2021).

319 32. F. Kirstein, N. E. Nieuwenhuizen, J. Jayakumar, W. G. C. Horsnell, F.

Brombacher, Role of IL-4 receptor a-positive CD4+ T cells in chronic airway hyperresponsiveness. J. Allergy Clin. Immunol. (2015), doi:10.1016/j.jaci.2015.10.036.

33. T. Wu, E. Hu, S. Xu, M. Chen, P. Guo, Z. Dai, T. Feng, L. Zhou, W. Tang, L. Zhan, X. Fu, S. Liu, X. Bo, G. Yu, clusterProfiler 4.0: A universal enrichment tool for interpreting omics data. Innov. 2 (2021), doi:10.1016/j.xinn.2021.100141. 

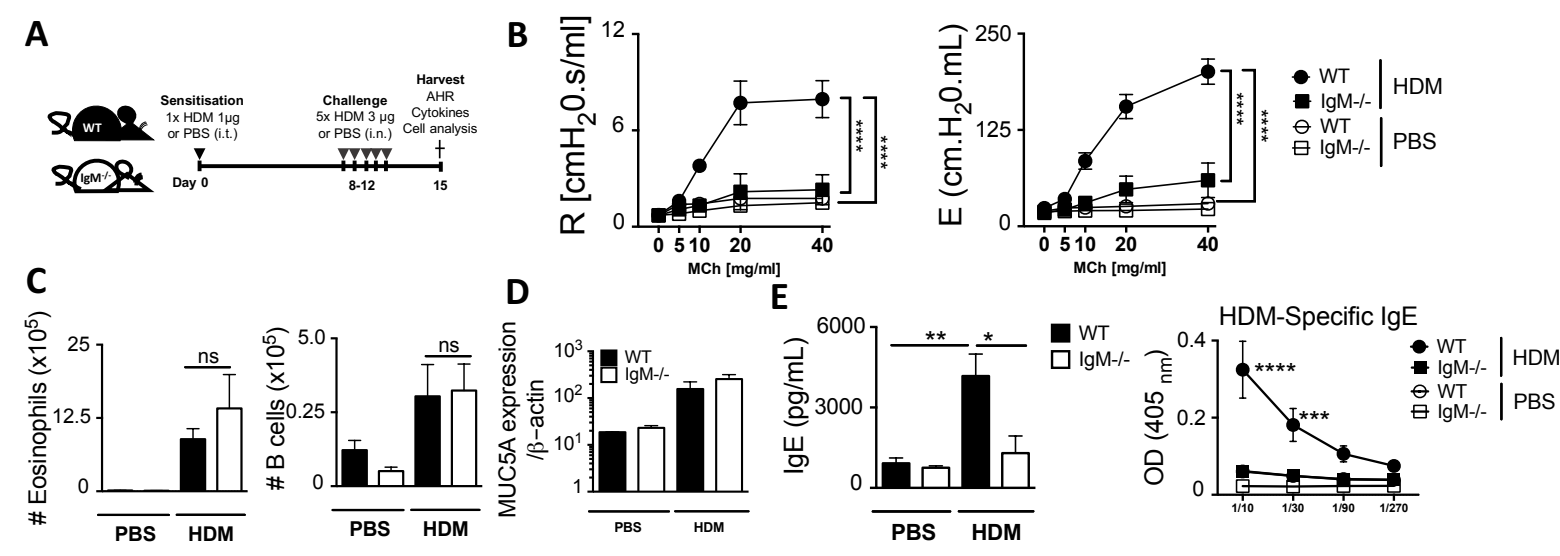

$F$

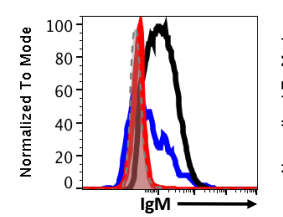

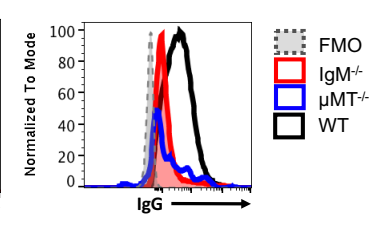

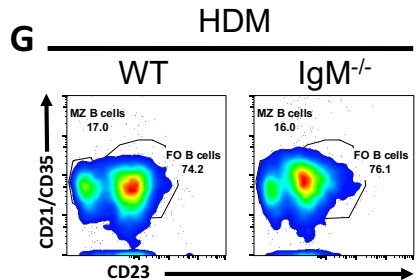

330

Fig. 1. IgM-deficiency leads to reduced airway hyperresponsiveness and class switching to IgE in HDM-induced asthma.

(A) Schematic diagram showing sensitisation and challenge protocol where mice (IgM${ }^{-}$) and wild type littermate control (WT) were sensitised with HDM $1 \mu \mathrm{g}$ intra-tracheally on days 0 and challenged with HDM $3 \mu \mathrm{g}$ on days 8-12. Analysis was done on day 15 .

(B) Airway resistance and elastance were measured with increasing doses of acetyl methacholine $(0-40 \mathrm{mg} / \mathrm{mL})$.

(C) Total lung eosinophil numbers $\left(\right.$ live ${ }^{+}$Siglec- $\left.\mathrm{F}^{+} \mathrm{CD} 11 \mathrm{c}^{-}\right)$and $\mathrm{B}$ cells (live ${ }^{+} \mathrm{B} 220^{+} \mathrm{CD} 19^{+} \mathrm{MHClI}^{+}$) were stained and analysed by Flow cytometry and enumerated from $\%$ of live cells.

(D) Muc5a gene expression in whole lung tissue.

(E) Total lgE and HDM-specific IgE in serum. 
343 (F) IgG1 and IgM surface expression in mediastinal lymph node B cells of WT, $\operatorname{lgM}^{-/-}$ 344 and $\mu \mathrm{MT}^{-/-}$mice.

345 (G) Marginal Zone (live ${ }^{+} \mathrm{B} 220^{+} \mathrm{CD} 19^{+} \mathrm{MHCl}^{+} \mathrm{CD} 21 / \mathrm{CD}^{2} 5^{+} \mathrm{CD}^{2}{ }^{-}$), follicular 346 (live ${ }^{+} \mathrm{B} 220^{+} \mathrm{CD} 19^{+} \mathrm{MHCII}{ }^{+} \mathrm{CD} 23^{+} \mathrm{CD} 21 / \mathrm{CD} 35^{+}$) and Germinal Centre 347 (live ${ }^{+} \mathrm{B} 220^{+} \mathrm{CD} 19^{+} \mathrm{MHCII}^{+} \mathrm{GL7}^{+} \mathrm{FAS}^{+}$) B cells in mediastinal lymph node of WT and $\operatorname{lgM}^{-}$ 348 I- mice challenged with HDM.

349 Shown is mean \pm SEM from two pooled experiment $(n=10-12)$. Significant differences 350 between groups were performed by Student $t$-test (Mann-Whitney) (C, D, E) or by 351 Two- Way ANOVA with Benforroni post-test (B) and are described as: ${ }^{*} p<0.05$, $352{ }^{* *} p<0.01,{ }^{* * *} p<0.001,{ }^{* * *} p<0.0001$. 


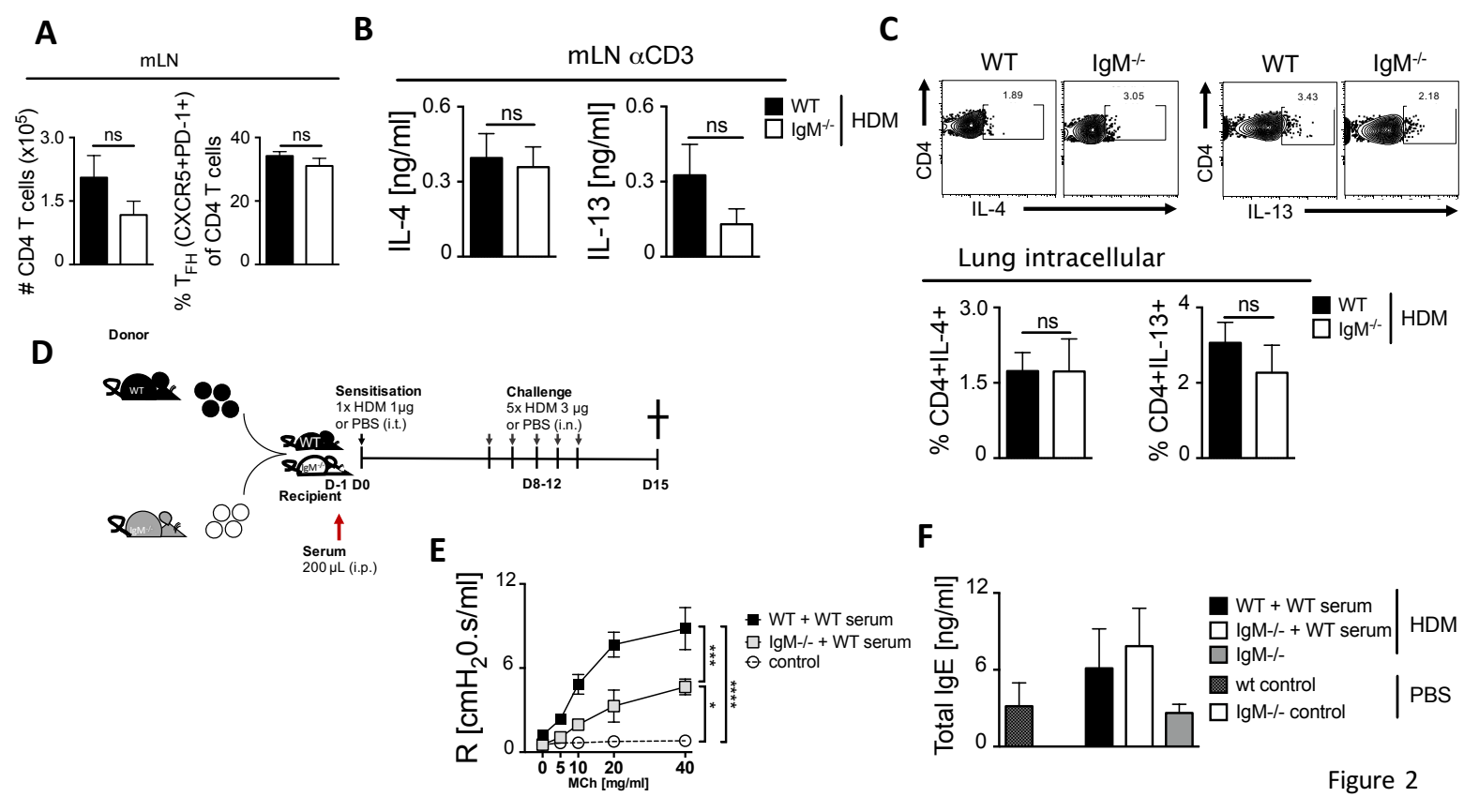

Fig. 2. IgM-deficiency does not lead to reduced Th2 allergic airway inflammation and serum transfer restores IgE, but not AHR.

357

(A) Total mediastinal lymph node CD4 $\mathrm{T}$ cell numbers $\left(\right.$ live ${ }^{+} \mathrm{CD} 3^{+} \mathrm{CD} 4^{+}$) and $\%$ of

358 Follicular Helper $\mathrm{T}$ cells (live ${ }^{+} \mathrm{CD} 3^{+} \mathrm{CD} 4^{+} \mathrm{PD}-1^{+} \mathrm{CXCR} 5^{+}$) of $\mathrm{CD} 4 \mathrm{~T}$ cells were stained and analysed by Flow cytometry and enumerated from \% of live cells.

360

(B) Mediastinal lymph nodes were stimulated with anti-CD3 $(10 \mu \mathrm{g} / \mathrm{mL})$ for 5 days and

361 supernatants were used to measure levels of IL-4 and IL-13. Cytokines were not detected in unstimulated or HDM $(30 \mu \mathrm{g})$ stimulated $\mathrm{mLN}$.

(C) Representative FACS plots and frequencies of lung CD4 T cells (live ${ }^{+} \mathrm{CD} 3^{+} \mathrm{CD} 4^{+}$)

364 producing IL-4 and IL-13 after $5 \mathrm{hr}$ stimulation with PMA/ionomycin in the presence of 365 monensin.

366 (D) Schematic diagram showing serum transfer from WT to $\operatorname{lgM}^{-/-}$which were then sensitised as shown in Fig. 1,A. 
368 (E) Airway resistance was measured with increasing doses of acetyl methacholine (0 $369-40 \mathrm{mg} / \mathrm{mL})$.

370 (E) Total IgE in serum of mice either transferred with WT serum, $\operatorname{lgM}^{-/-}$serum or no 371 serum.

372 Shown is mean \pm SEM from two pooled experiment $(n=10-12)$. Significant differences 373 between groups were performed by Student $t$-test (Mann-Whitney) (C, D, E) or by 374 Two-Way ANOVA with Benforroni post-test $(B)$ and are described as: ${ }^{*} p<0.05$, 375 ${ }^{* *} p<0.01,{ }^{* * *} p<0.001,{ }^{* * * *} p<0.0001$.

376

377 
A
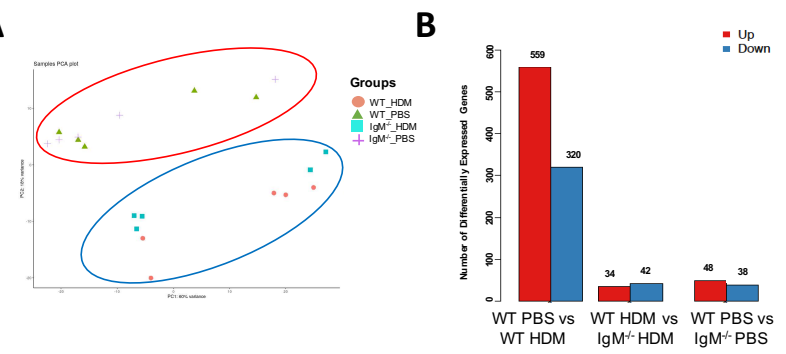

D

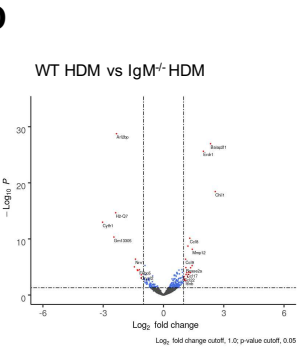

E

WT PBS vs IgM ${ }^{-}-\mathrm{PBS}$
C

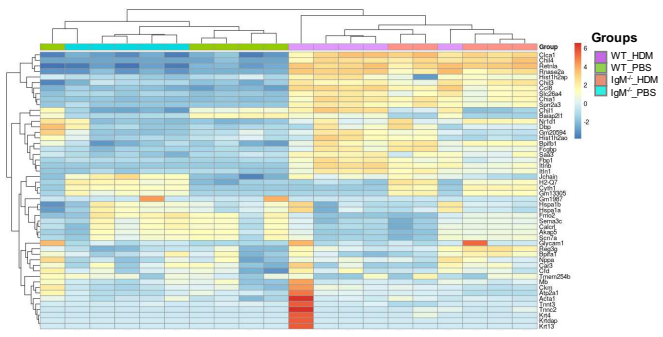

$\mathbf{F}$



379 Fig. 3. Genes associated with muscle contraction are downregulated in IgM-

deficient mice. WT and $\operatorname{lgM}^{-/-}$mice were treated as in Fig. 1A and RNA collected

381

382

383

384

385

386

387

388

389

390

391

392

393

from whole lung for RNA sequencing.
(A) Principal-component (PC) analysis showing variation in the global gene expression profiles across the different groups. PC1 (60\%) and PC2 (18\%), which capture the greatest variation in gene expression, are shown. Orange colour represents WT HDM, green colour represents WT PBS, Blue colour represents $\operatorname{lgM}^{-1-}$ HDM and purple crosses represent $\operatorname{lgM}^{-/-}$PBS. Each dot represents an individual mouse.

(B) Number of differentially expressed genes between groups.

(C) Heatmaps depicting the differently expressed genes between WT and $\operatorname{lgM}^{-1-}$ samples from HDM treated and PBS mice ranked based on hierarchical clustering. (D-E) Volcano plots: numbers and colour relate to genes that have an adjusted $p$ value $<0.05$. Blue, significantly downregulated; red, significantly up-regulated; grey, non-differentially expressed. P values were adjusted for multiple testing using the 
394 Benjamini-Hochberg method. (D) represent changes between WT and $\operatorname{lgM}^{-/-}$treated 395 with $\mathrm{HDM}$ and $(\mathrm{E})$ represents changes between $\mathrm{WT}$ and $\mathrm{IgM}^{-/-}$treated with saline. 396 (F) Gene set enrichment analysis (GSEA) of hallmark gene sets from the Molecular 397 Signatures Database of the Broad Institute, showing the normalized enrichment 398 scores (NES) for lung RNA-Seq data from WT mice.

399

400 
A

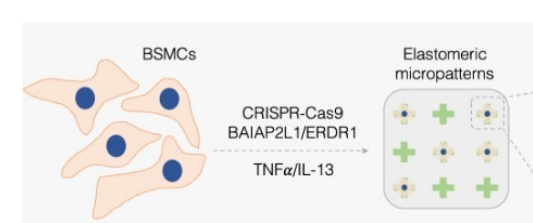

B

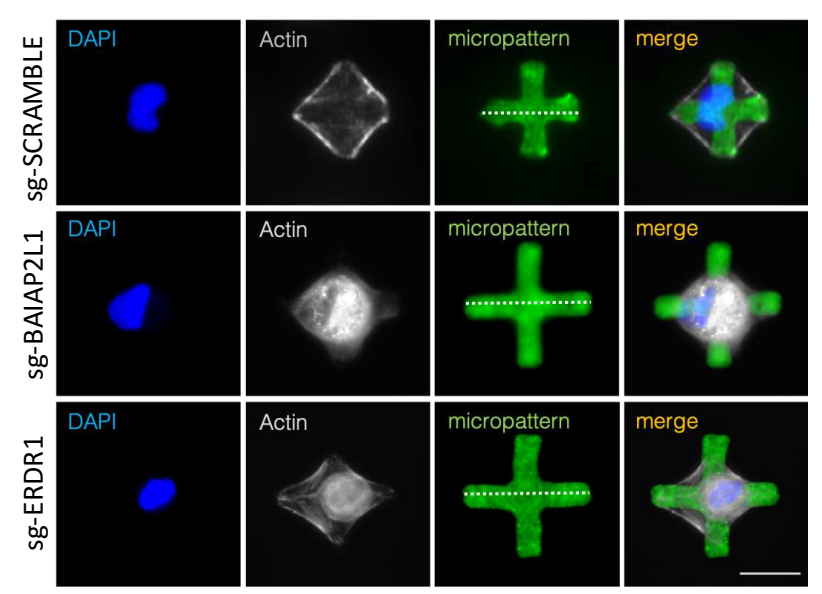

401

402

Fig. 4. CRISPR-based deletion of BAIAP2L1 and ERDR1 leads to reduced

403 smooth muscle contraction at a single cell level.

404

(A) Bronchial smooth muscle cells (1.6x105 cells/well) were transfected with

405

CRISPR-Cas9 single guide RNAs (scramble, BAIAP2L1 and ERDR1), stimulated

406

with recombinant human IL-13 $(100 \mathrm{ng} / \mathrm{mL})$ and TNF- $\alpha(10 \mathrm{ng} / \mathrm{mL})$ for $48 \mathrm{~h}$. Cells

407

were then transferred to elastomeric micropatterns, stimulated again with $\mathrm{rlL}-13$ and

408 rTNF- $\alpha$ and fixed before imaging on a StellarVision microscope.

409 (B) Representative images of single BSMCs on micropatterns from scramble,

410 BAIAP2L1 and ERDR1 stimulated with $10 \mathrm{ng} / \mathrm{mL}$ TNF- $\alpha$. DNA was stained with

411 DAPI, actin fibers with Phaloidin-565 and elastomeric micropatterns are coated in

412 Fibronectin-488. Merged images are shown on the right.

413 (C) Violin plots showing contraction of 50-100 cells/condition stimulated with 10

$414 \mathrm{ng} / \mathrm{mL}$ TNF- $\alpha$, individual dots represent a single cell contraction, where blue is

415 scramble sgRNA, red is BAIAP2L1 sgRNA and green is ERDR1 is sgRNA.

416 (D) Violin plots showing contraction of 50-100 cells/condition stimulated with 100 
$417 \mathrm{ng} / \mathrm{mL} \mathrm{IL-13}$, individual dots represent a single cell contraction, where blue is 418 scramble sgRNA, red is BAIAP2L1 sgRNA and green is ERDR1 is sgRNA.

419

420 Shown is mean \pm SEMs from two pooled experiment $(n=50-100)$. Significant

421 differences between groups were performed by student t-test (Mann-Whitney) and $p$

422 value is shown.

423 
424 Supplementary Materials for

425

426 IgM regulates airway hyperresponsiveness via modulation of actin associated genes.

427

428 Sabelo Hadebe1* ${ }^{*}$ Anca Flavia Savulescu ${ }^{2}$, Jermaine Khumalo ${ }^{1}$, Katelyn Jones ${ }^{1}$,

429 Sandisiwe Mangali ${ }^{1,3}$, Nontobeko Mthembu ${ }^{1}$, Amkele Ngomti ${ }^{1}$, Martyna Scibiorek ${ }^{1,3}$,

430 Javan Okendo 2,5 , Frank Brombacher ${ }^{1,3,4}$ *

431

432 Correspondence to brombacherfrank@gmail.com; saabelo.hadebe@uct.ac.za

433

434

435 
IgM-deficient homozygotes mice on Balb/C background and on C57BL/6 background were backcrossed up to 10 generations (21). Wild type on Balb/C and C57BL/6 background were used as a littermate control. Mice were housed in independently ventilated cages under specific pathogen-free conditions at the University of Cape

442 Town Animal Facility. All mice were used at eight to 10 weeks of age and animal procedures were performed according to strict recommendation by the South African Veterinary Council and were approved by the University of Cape Town Animal Ethics Committee (Reference number 018/013).

House Dust-mite induced allergic airway disease

A high dose and a low dose treatment schedule were used to induce symptoms of allergic asthma in mice (31). Mice were anaesthetised with ketamine (Anaket-V; Centaur Labs, Johannesburg, South Africa) and xylazine (Rompun; Bayer, Isando, South Africa). Mice were sensitised intratracheally (i.t.) on day 0 with $1 \mu \mathrm{g}$ of HDM

452 (Stellergens Greer Laboratories, Lenoir, U.S.A.) and intranasally challenged with 3 ug HDM on days 8, 9, 10, 11 and 12. AHR was measured on day 15. After the procedure, mice were euthanised and tissue samples were collected for analysis.

Adoptive transfer of naïve $B$ cells

457 Spleens were collected from naïve congenic CD45.1 Balb/C mice and passed through $40 \mu \mathrm{m}$ strainer to obtain single cell suspensions. Cells were stained with FITC-B220 and APC-CD19 for $30 \mathrm{~min}$ at $4^{\circ} \mathrm{C}$. A dead cell exclusion dye (7AAD) was

460 added before sorting on BD FACS Aria I to at least $96 \%$ purity. $2-5 \times 10^{6}$ cells were 
461 adoptively transferred intravenously (i.v.) into $\lg ^{-/-}$recipient mice a day before HDM

462

463

464

465

466

467

468

469

470

471

472

473

474

475

476

477

478

479

480

481

482

483

484

485 sensitisation.

Adoptive transfer of naïve serum

Naïve wild type mice were euthanised and blood collected via cardiac puncture before being spun down to collect serum. Serum $(200 \mu \mathrm{L})$ was injected intraperitoneally into IgM-deficient mice, 1 day before sensitisation with HDM.

\section{Ovalbumin induced allergic airway inflammation}

Mice were sensitised intraperitoneally with $(50 \mu \mathrm{g}$ in $200 \mu \mathrm{l})$ of ovalbumin (OVA) adsorbed to $0.65 \%$ alum (Sigma-Aldrich, Aston Manor, South Africa) on days 0, 7, 14. On days $23,24,25$, mice were intranasally challenged with $100 \mu$ g of OVA under anaesthesia with ketamine (Anaket-V; Centaur Labs, Johannesburg, South Africa) and xylazine (Rompun; Bayer, Isando, South Africa). AHR was measured on day 26. After the procedure, mice were euthanized with halothane and tissue samples collected for analysis.

\section{Papain-induced lung inflammation}

Mice were sensitised with isoflourane $(3 \mathrm{~L} / \mathrm{min})$ briefly before being challenged with $50 \mu \mathrm{L}$ of $25 \mu \mathrm{g}$ of Papain (Sigma-Aldrich, Aston Manor, South Africa) on days 1, 2 and 3 or PBS. AHR was measured on day 4 . After the procedure, mice were euthanized with halothane and tissue samples collected for analysis. 
487 Airway resistance and elastance of the whole respiratory system (airways, lung chest

488

489

490

491

492

493

494

495

496

497

498

499

500

501

502

503

504

505

506

507

508

509

510

wall) after intranasal challenge was determined by forced oscillation measurements as described previously (32) with the Flexivent system (SCIREQ, Montreal, Canada) by using the single compartment ("snapshot") perturbation. Measurements were carried out with increasing doses of acetyl- $\beta$-methylcholine (methacholine, SigmaAldrich, Aston Manor, South Africa) (0, 5, 10, 20 and $40 \mathrm{mg} / \mathrm{mL})$ for Balb/C or $(0,20$, 40, 80160 and $320 \mathrm{mg} / \mathrm{mL}$ ) for C57BL/6. Differences in the dose-response curves were analysed by repeated-measures Two-way ANOVA with the Bonferroni posttest. Only mice with acceptable measurements for all doses (coefficient of determination $>0.90$ ) were included in the analysis.

\section{Flow cytometry}

Single-cell suspensions were prepared from lymph nodes in Roswell Park Memorial Institute (RPMI) media (Gibco, Paisley, United Kingdom) by passing them through $100 \mu m$ strainer. To obtain single cell suspensions from lung tissues, a left lobe was digested for 1 hour at $37^{\circ} \mathrm{C}$ in RPMI containing $13 \mathrm{mg} / \mathrm{mL}$ DNase I (Roche, Randburg, South Africa) and $50 \mathrm{U} / \mathrm{mL}$ collagenase IV (Gibco, Waltham, Massachusetts) and passed through $70 \mu \mathrm{m}$ strainer. Antibodies used in these experiments included, phycoerythrobilin (PE)- conjugated anti-Siglec-F (clone, E502440), anti-IL-5 (clone, TRFK5), anti-CD44 (clone, KM114), anti- T and B cell activation antigen (clone, GL7), anti-CD43 (clone, S7), FITC- conjugated anti-Ly6G (clone, 1A8), anti-IgD (clone, 11-26C2a), IL-4 (clone, 11B11), anti-PD-1-(clone, 29F.1A12), PerCP Cy5.5- conjugated anti-Ly6C (clone, AL-21), -CD45.1 (clone, A20), anti-IL-17 (clone, TC11-18H10), Allophycocyanin (APC)- conjugated anti- 
511 CD11c (clone, HL3), anti-CD5 (clone, 53-7.3), BV421 conjugated anti-CD11b (clone,

512 M1/70), anti-CD62L (clone, MEL-14), anti-IgG1 (clone, A110-1), AlexaFlour 700-

513 conjugated anti-CD3ع (clone, 145-2C11) -anti IFN-y, BV510- anti-CD4 (clone, RM4-

514 5) and anti- B220 (clone, RA3-6B2), APC-Cy7-conjugated anti-CD19 (clone, 1D3)

515 and anti-CD8 (clone, 53-6.7), BV786 conjugated anti-IgE (clone, R35-72) and anti-IL-

516 33R (ST2) (clone, U29-93), biotin-conjugated anti-IgM (clone, AF-78), anti-CD95

517 (clone, Jo2), anti- CD249 (clone, BP-1) were purchased from BD Pharmingen (San

518 Diego, CA). PE-Cynanine7 anti-F4/80 (clone, BM8), anti-IL-13 (clone, eBio13A), anti-

519 CXCR5 (clone, L138D7), AlexaFlouro 700- conjugated anti-MHC II (clone, M5/114),

520 Live/dead Fixable Yellow stain (Qdot605 dead cell exclusion dye) were purchased

521 from eBiosciences. Biotin-labelled antibodies were detected by Texas Red

522 conjugated PE (BD Biosciences). For staining, cells $\left(1 \times 10^{6}\right)$ were stained and

523 washed in PBS, 3\% FCS FACS buffer. For intracellular cytokine staining, cells were

524 restimulated with phorbal myristate acetate (Sigma-Aldrich) $(50 \mathrm{ng} / \mathrm{mL})$, ionomycin

525 (Sigma-Aldrich) (250ng/mL), and monensin (Sigma-Aldrich) (200mM in IMDM/10\%

526 FCS) for $5 \mathrm{~h}$ at $37^{\circ} \mathrm{C}$ then fixed in $2 \%$ PFA, permeabilised with Foxp3 transcriptional

527 factor staining buffer kit (eBioscience) before intracellular staining with appropriate

528 cytokine antibodies and acquisition through LSR Fortessa machine (BD

529 Immunocytometry system, San Jose, CA, USA) and data was analysed using Flowjo

530 software (Treestar, Ashland, OR, USA).

531

532 Histology

533 Left upper lung lobes was fixed in 4\% formaldehyde/PBS and embedded in paraffin.

534 Tissue sections were stained with periodic acid-Schiff for mucus secretion, and

535 haematoxylin and eosin (H\&E) stain for inflammation. Slides were scanned at 20x 
magnification on the virtual slide VS120 microscope (Olympus, Japan). Downstream processing of images was done through Image $\mathrm{J}(\mathrm{FI} I)$ for image extraction at series 15 and llastik software was used for mucus area quantification on whole lung sections. Data shown is representative of 1 experiment of 3 independent experiments ( $n=5-7$ mice per experiment).

542 Antibody and cytokine ELISAs

543 Antibody ELISAs were carried out as previously described using $10 \mu \mathrm{g} / \mathrm{ml}$ HDM to 544 coat for specific IgGs. Total IgE in serum was measured using anti-mouse IgE (BD 545 Biosciences, 553413) to coat, mouse IgE ( $\mathrm{k}$, anti-TNP, BD Biosciences, 557079) as

546 standard and biotin anti-mouse lgE (BD Biosciences, 553419) as secondary 547 antibody.

548 For in vitro cytokine production analysis, single cell suspensions were prepared from 549 mediastinal lymph nodes of HDM-treated and littermate control mice. Cells (2x10 550 cells, in $200 \mu \mathrm{L}$ ) were incubated for 5 days in RPMI/10\% FCS (Delta Bioproducts, 551 Kempton Park, South Africa) in 96-well plates. Cells were either stimulated with HDM

$552(30 \mu \mathrm{g} / \mathrm{mL})$ or anti-CD3 $(10 \mu \mathrm{g} / \mathrm{mL})$ and supernatants were collected after a 5-day 553 incubation period. Concentrations of IL-4, IL-5 (BD Biosciences) and IL-13 (R\&D 554 Systems, Minneapolis, Minn), were measured using ELISA assays according to the 555 manufacturer's protocol.

RNA Extraction

558 Small lung lobe was frozen in Qiazol (Qiagen, Germany) and stored at $-80^{\circ} \mathrm{C}$. Total

559 RNA was isolated from the lysate using miRNeasy Mini kit (Qiagen, Germany)

560 according to the manufacturer's instructions. RNA quantity and purity were 
measured using the ND-1000 NanoDrop spectrophotometer (ThermoScientific, DE,

562 USA).

563

564 cDNA Synthesis and RT-qPCR

565 For Muc5a gene expression analysis, 100 ng total RNA was reverse-transcribed into 566 cDNA using Transcriptor First Strand cDNA Synthesis Kit (Roche, Germany)

567 according to the manufacturer's instructions. Quantitative real-time PCR (RT-qPCR) was performed using LightCycler® 480 SYBR Green I Master (Roche, Germany) and Muc5a primers (IDT, CA, USA). Fold change in gene expression was calculated by the $\Delta \Delta$ Ct method and normalized to ß-actin which was used as an internal

571 control.

572

573

Whole lung RNA sequencing

574 Whole lung RNA was extracted using RNAeasy kit (Qiagen, Germany) according to 575 the manufacturer's instructions. We used Agilent 2100 Bio analyzer (Agilent RNA 5766000 Nano Kit) to do the total RNA sample QC: RNA concentration, RIN

577 value,28S/18S and the fragment length distribution. The first step in the workflow 578 involved purifying the poly-A containing mRNA molecules using poly-T oligo attached magnetic beads. Following purification, the mRNA was fragmented into small pieces

580 using divalent cations under elevated temperature. The cleaved RNA fragments

581 were copied into first strand cDNA using reverse transcriptase and random primers.

582 This was followed by second strand cDNA synthesis using DNA Polymerase I and

583 RNase $H$. These cDNA fragments had addition of a single 'A' base and subsequent

584 ligation of the adapter. The products were then purified and enriched with PCR

585 amplification. PCR yields were quantified by Qubit and pooled samples together to 
make a single strand DNA circle (ssDNA circle), which gave the final library. DNA

587

588

589

590

591

592

593

594 Bioinformatics workflow

595

596

597

598

599

600

601

602

603

604

605

606

607

608

609

610 single guide RNAs.

nanoballs (DNBs) were generated with the ssDNA circle by rolling circle replication $(\mathrm{RCR})$ to enlarge the fluorescent signals at the sequencing process. The DNBs were loaded into the patterned nanoarrays and pair-end reads of $100 \mathrm{bp}$ were read through on the DNBseq platform for the following data analysis study. For this step, the DNBseq platform combines the DNA nanoball-based nanoarrays and stepwise sequencing using Combinational Probe-Anchor Synthesis Sequencing Method.

The ribosomal RNA (rRNA) was first removed using SortMeRNA. We then did the Fastq file quality control using Fastqc and multiqc software to assess the quality of the raw reads followed by adapter trimming using Trim galore The reads were then aligned to the mouse reference genome (mm10_UCSC_20180903) using STAR aligner. The map read counts was then extracted using featurecounts. The gene differential analysis was conducted using the DEseq2. The genes with LFC $>=2$ and adjusted $p$-value <= 0.05 was used to do the gene ontology over-representation analysis done using clusterProfiler(33) Bioconductor package. The BanjaminiHochnurg method was used for multiple test correction.

\section{Human bronchial Airway Smooth Muscle cell culture}

Human bronchial smooth muscle cell line (BSMC, Lonza) was cultured in Smooth Muscle Growth Medium (Lonza) with 5\% (vol/vol) FCS in a T25 flask (Lonza) until confluence. After two passages in T75 flask, confluent cells were seeded at $1.6 \times 10^{5}$ BSMC cells onto 24-well trays and immediately transfected with CRISPR/Cas9 
612 single guide RNAs targeting human BAIAP2L1 (\# CD.Cas9.CXVQ6494.AA);

613 ERDR1, (\# CD.Cas9.YFVV2490.AA); HPRT Negative Control (\#Alt-R® CRISPR-

614 Cas9crRNA) were purchased (IDT, CA, USA via WhiteScientific PTY LTD). Single

615 guide RNA $(1 \mu \mathrm{M})$ and Cas9 enzyme $(1 \mu \mathrm{M})$ in Opti-MEM medium (Life

616 Technologies $^{\mathrm{TM}}$, Carlsbad, CA, USA) was transfected using Lipofectamine RNAi

617 Max 1000 (Thermo Scientific) into BSMC cells $\left(1.6 \times 10^{5}\right)$ per well for 48 hours. Gene

618 deletion was confirmed by DNA extraction (Wizard Genomic DNA Purif. Kit,

619 Promega) and PCR amplification of target genes using BAIAP2L1 forward

620 (GTCCCGGGGGCCCGA) and reverse (AAGCGCCCAAGAATGTGGGG) primers.

621

622

Cytotoxic detection Assay

623 To measure cytotoxicity after single guide RNA transfection, lactate dehydrogenase

624 (LDH) was measured in supernatants collected at 48 hours post transfection using

625 cytotoxicity detection kit PLUS Assay (CYTODET-RO, Roche) according to

626 manufacturer's instructions and plates were read at $490 \mathrm{~nm}$.

627

628 Single cell force cytometry using Fluorescently Labelled Elastomeric Contractible

629 Surface (FLECS) technology

630 BSMCs were seeded on Fibronectin-coated elastomeric micropatterns (Forcyte

631 Biotechnologies \#F2AX0G03Y, 50 micron, Alexa Fluor 488 - bound Fibrinogen, 24-

632 well plate) at a concentration of 75,000 cells per well in Smooth muscle growth

633 medium (SmGM) (Lonza) and left to adhere and spread for 90 minutes. Unattached

634 cells were then removed and fresh SmGM medium supplemented with rhTNF- $\alpha$ (10

$635 \mathrm{ng} / \mathrm{mL}) / \mathrm{rhlL}-13(100 \mathrm{ng} / \mathrm{mL}) / \mathrm{ACh}(10 \mu \mathrm{M})$ was added. BSMCs were stimulated for 3 
$636 \mathrm{hrs}$ before being fixed in pre-warmed to $37^{\circ} \mathrm{C} 4 \%$ PFA. Fixed samples were washed

637 then stained with ATTO-565 phalloidin (ATTO-TEC) and DAPI (Life Technologies)

638 and imaged on a StellarVision microscope using Synthetic Aperture Optics

639 technology (Optical Biosystems). All images were analyzed using FiJi software.

640

641 Statistical analysis

642 P-values were calculated in GraphPad Prism 6 (GraphPad Software, Inc) by using

643 nonparametric Mann-Whitney Student's t-test or Two-way ANOVA with Bonferroni's

644 post-test for multiple comparisons, and results are presented as standard error of the

645 mean (SEM) or mean of standard deviation (SD). Differences were considered

646 significant if $P$ was $<0.05$.

647

648 
650 Fig. S1.

A



B

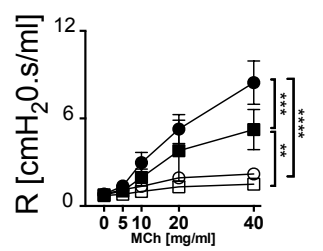

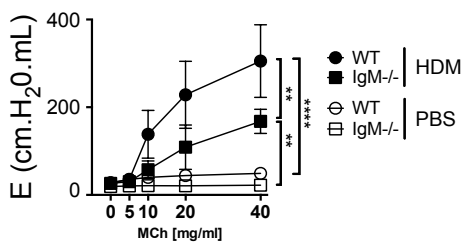

C D E
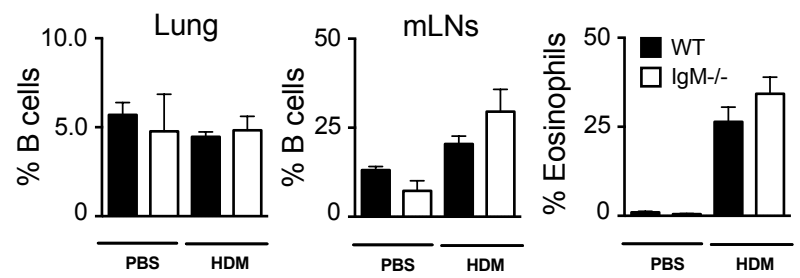

E

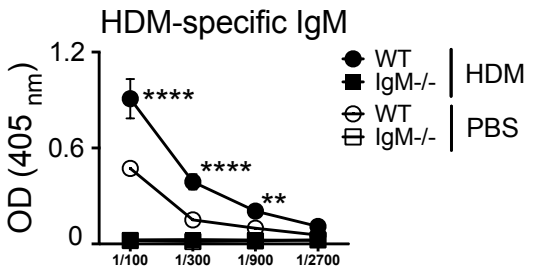

Supplementary Figure 1

651

652 IgM-deficiency leads to reduced airway hyperresponsiveness, but eosinophils

653 and $B$ cells are unaffected.

654 (A) Schematic diagram showing sensitisation and challenge protocol where mice $\left(\operatorname{lgM}^{-}\right.$ 655 I-) and wild type littermate control (WT) were sensitised with HDM $100 \mu \mathrm{g}$ intra656 tracheally on days 0 and challenged with HDM $10 \mu \mathrm{g}$ on days 8-12. Analysis was done 657 on day 15.

658 (B) Airway resistance and elastance were measured with increasing doses of acetyl 659 methacholine $(0-40 \mathrm{mg} / \mathrm{mL})$.

660 (C) Frequencies of lung and mediastinal lymph node B cells (live ${ }^{+} \mathrm{B}^{2} 20^{+} \mathrm{CD} 19^{+} \mathrm{MHClI}^{+}$) 661 and were stained and analysed by Flow cytometry.

662 (D) Frequencies of lung eosinophils (live ${ }^{+}$Siglec- $\mathrm{F}^{+} \mathrm{CD} 11 \mathrm{c}^{-}$) were stained and analysed 663 by Flow cytometry. 
664 (E) HDM-specific IgM in serum

665 Shown is mean \pm SEMs from two pooled experiment $(n=10-12)$. Significant 666 differences between groups were performed by Two way ANOVA with Benforroni 667 post-test and are described as: ${ }^{*} p<0.05,{ }^{* *} p<0.01,{ }^{* * *} p<0.001,{ }^{* * *} p<0.0001$.

668 
A


C


671 Reduced airway hyperresponsiveness in IgM-deficient mice is independent of

672 mouse background in HDM induced asthma.

673 (A) Mice (lgM ${ }^{-/-}$and WT) were sensitised and challenged as in Fig. 1, A and Airway 674 resistance and elastance were measured with increasing doses of acetyl 675 methacholine $(0-320 \mathrm{mg} / \mathrm{mL})$.

676 (B) Histology analyses of lung sections (magnification x20), stained with periodic acid677 Schiff. A.U., Arbitrary units.

678 (C) Total IgE, HDM-specific IgM, HDM-specific IgG1, HDM-specific IgG2a and HDM679 specific $\lg E$ in serum.

680 Shown is mean \pm SDs from 1 representative experiment of 2 independent experiments $681(n=4-6)$. Significant differences between groups were performed by student t-test 682 (Mann-Whitney) (C) or Two way ANOVA with Benforroni post-test and are described 683 as: ${ }^{*} p<0.05,{ }^{* *} p<0.01,{ }^{* * *} p<0.001,{ }^{* * * *} p<0.0001$ 
Fig. S3.
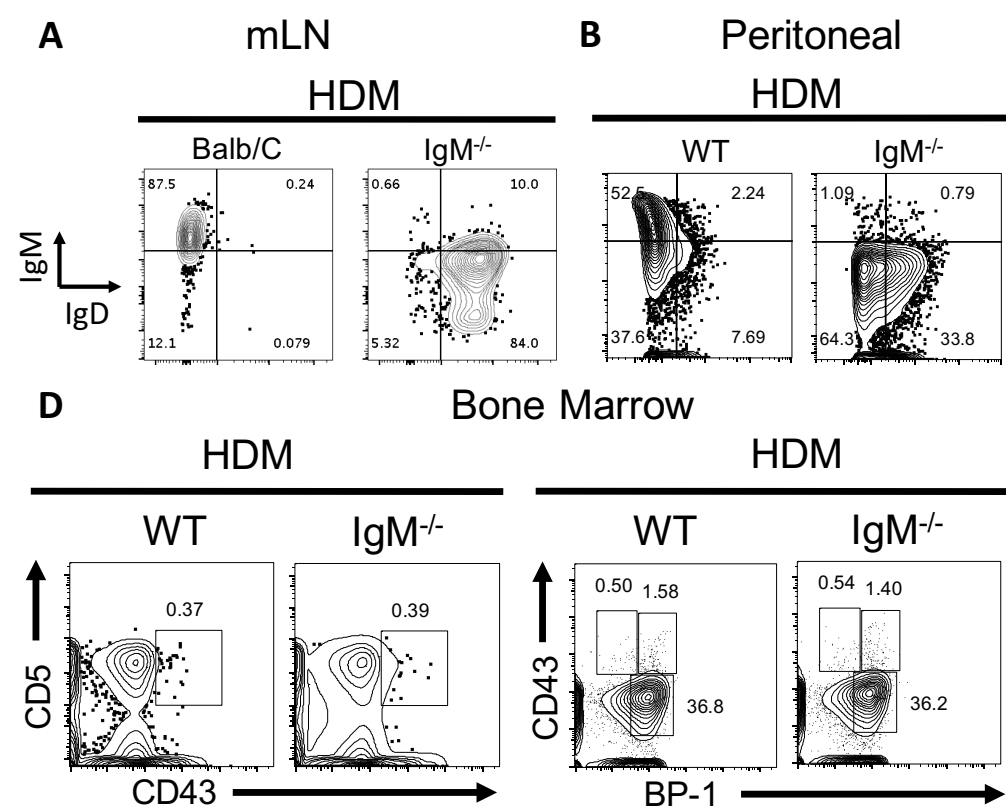

C Spleen

Bone Marrow

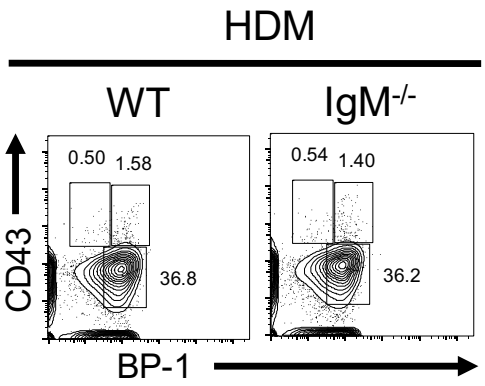

685

686 B cell development is not impacted by lack of $\lg M$, however, IgD expression is 687 upregulated in all tissues.

688 (A) B cell expression of $\lg M$ and $\lg D$ in $\lg ^{-/-}$and WT mice treated with HDM in 689 mediastinal lymph nodes, (B) Peritoneal and (C) Spleen.

690 (D) Bone marrow was flushed out $\operatorname{lgM}^{-/-}$and WT mice treated with HDM and stained 691 for B1 cells $\left(\mathrm{CD}^{+} \mathrm{CD} 43^{+}\right)$and pre-B cells $\left(\mathrm{CD} 43^{+} \mathrm{BP}-1^{+}\right)$. 
A

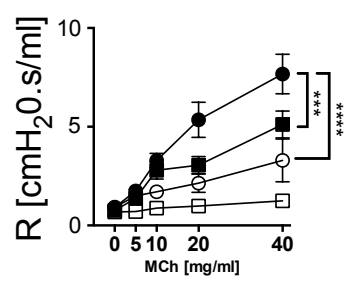

C
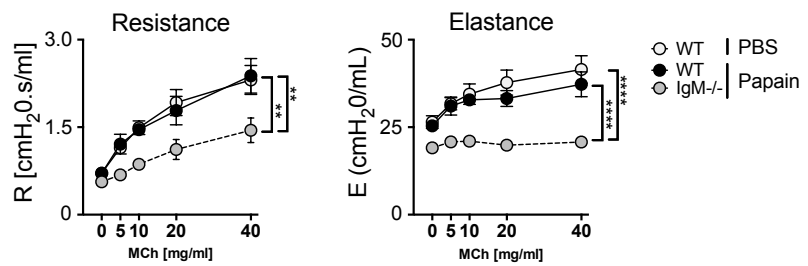

B
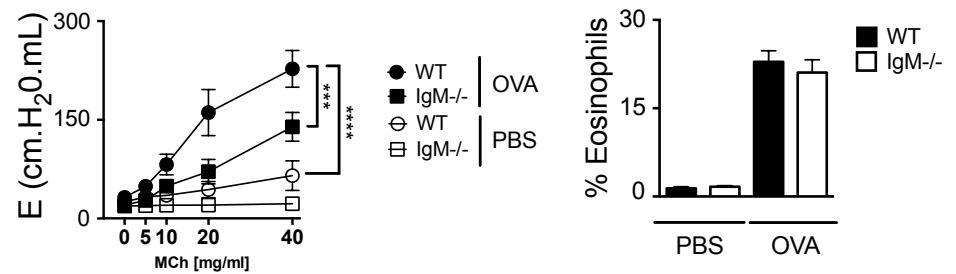

D

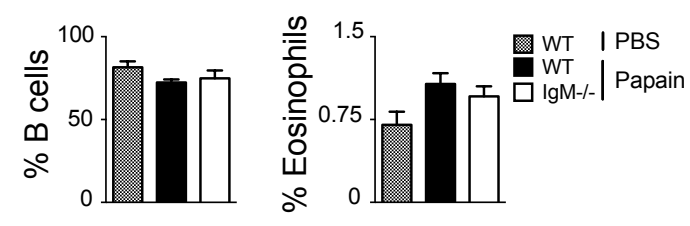

694 Reduced airway hyperresponsiveness in IgM-deficient mice is independent of 695 allergen

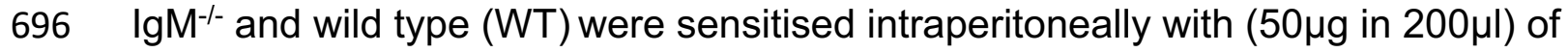
697 ovalbumin (OVA) adsorbed to $0.65 \%$ alum on days $0,7,14$. On days $23,24,25$, 698 mice were intranasally challenged with $100 \mu \mathrm{g}$ of OVA. AHR was measured on day 69926.

700 (A) Airway resistance and elastance were measured with increasing doses of acetyl 701 methacholine $(0-40 \mathrm{mg} / \mathrm{mL})$.

702

(B) Frequencies of lung eosinophils (live ${ }^{+}$Siglec $-\mathrm{F}^{+} \mathrm{CD} 11 \mathrm{c}^{-}$) were stained and analysed 703 by Flow cytometry.

704

(C) $\operatorname{lgM}^{-/-}$and wild type (WT) were challenged with $25 \mu \mathrm{g}$ of papain on days 1,2 and 3

705 or PBS. AHR was measured on day 4. Airway resistance and elastance were 706 measured with increasing doses of acetyl methacholine $(0-40 \mathrm{mg} / \mathrm{mL})$. 
707 (D) Frequencies of lung B cells $\left(\right.$ live $\left.{ }^{+} \mathrm{B} 220^{+} \mathrm{CD} 19^{+} \mathrm{MHCl}^{+}\right)$and eosinophils (live ${ }^{+}$Siglec$\left.708 \mathrm{~F}^{+} \mathrm{CD} 11 \mathrm{c}^{-}\right)$were stained and analysed by Flow cytometry.

709 Shown is mean \pm SEMs from two pooled experiment $(n=10-12)$. Significant 710 differences between groups were performed by Two way ANOVA with Benforroni 711 post-test and are described as: ${ }^{* *} p<0.01,{ }^{* * *} p<0.001,{ }^{* * *} p<0.0001$. 
Fig. S5.

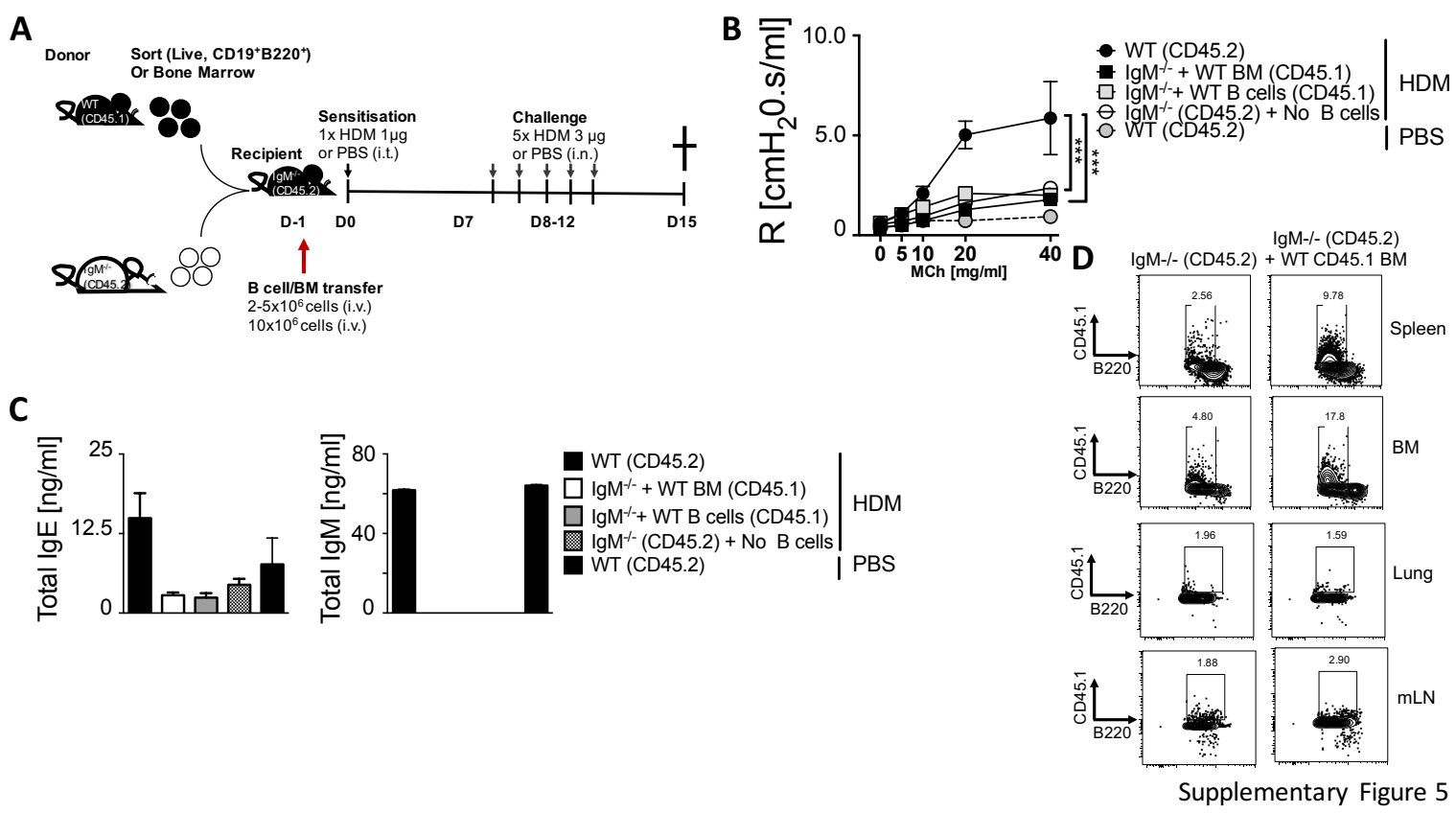

B cell and bone marrow reconstitution does not restore airway hyperresponsiveness in IgM-deficient mice in HDM induced allergic asthma.

716 (A) Schematic diagram showing sorted B cells (live ${ }^{+} B 220^{+}$CD19 $\left.{ }^{+}\right)\left(2-5 \times 10^{6}\right)$ or bone 717 marrow cells $\left(10 \times 10^{6}\right)$ transferred from congenic WT (CD45.1) to $\operatorname{lgM}^{-/-}$a day before 718 being sensitised as shown in Fig. 1,A.

719 (B) Airway resistance was measured with increasing doses of acetyl methacholine (0 $720-40 \mathrm{mg} / \mathrm{mL})$.

721 (C) Total IgE and IgM in serum of mice reconstituted with WT B cells or bone marrow.

722 (D) Representative FACS plots of CD45.1 cells in B220 cells (live ${ }^{+}$CD45. $1^{+} B 220^{+}$) IN 723 spleen, bone marrow, lung and mediastinal lymph nodes.

724 Shown is mean \pm SD from 1 experiment $(n=4-6)$. Significant differences between 725 groups were performed by Two-way ANOVA with Benforroni post-test and are 726 described as: ${ }^{* * *} p<0.001$. 
Fig. S6.

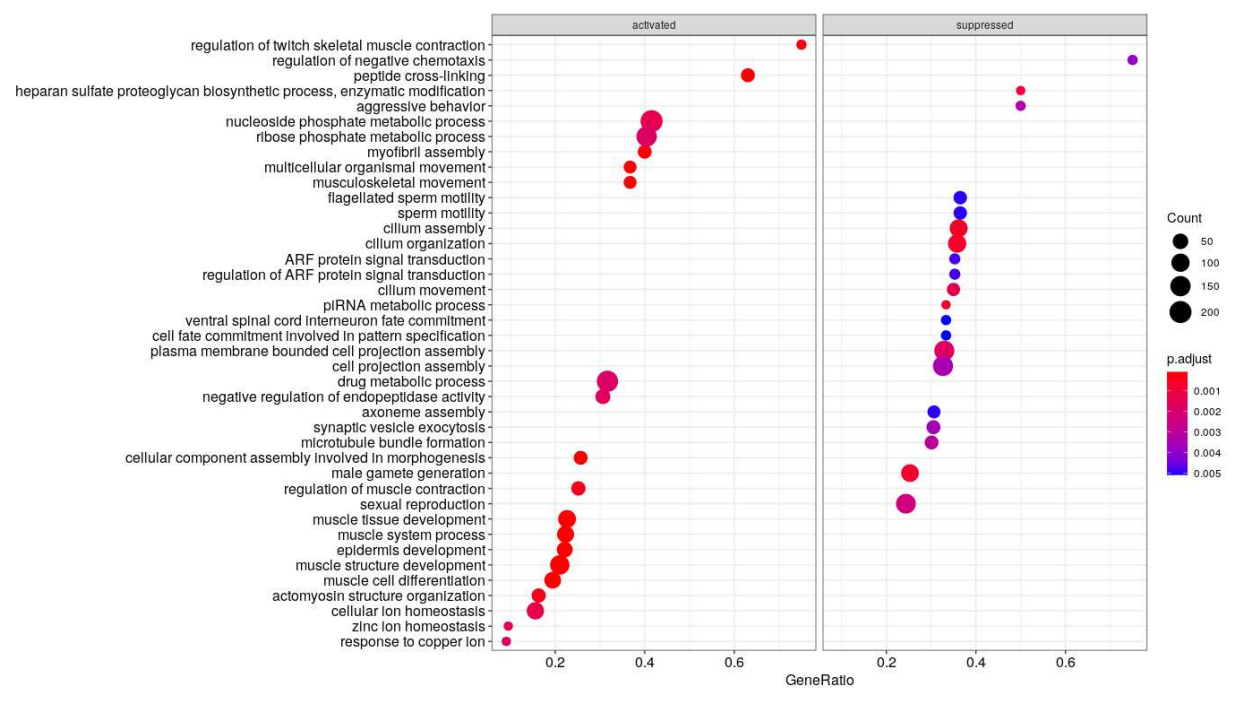

729 Genes associated with muscle contraction are downregulated in IgM-deficient

730 mice. Gene set enrichment analysis (GSEA) showing gene ratio of activated and

731 suppressed pathways from lung RNA-Seq data from WT mice and $\operatorname{lgM}^{-1-}$ mice.

732 Related to Fig. 3, F. 


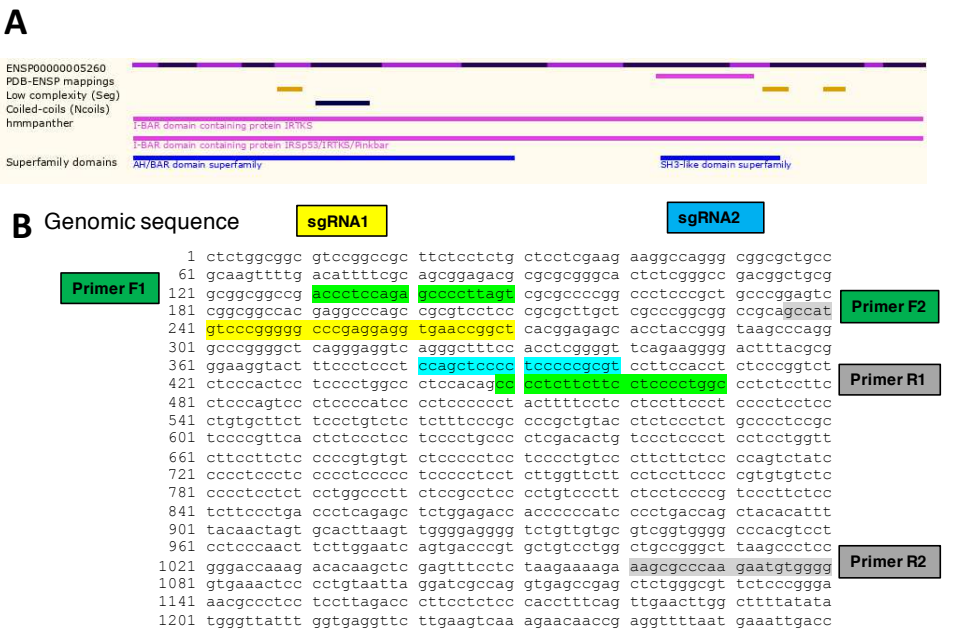

734

735

736

737

738

739

740

741

742

743

744

745

746

\section{Targeting and validation of BAIAP2L1 deletion by CRISPR.} IRTKS domain and C-terminal SH3-like domain. primer 1 regions (green) and primer 2 regions. PCR. media alone.
C


Supplementary Figure 7

(A) Schematic of human BAIAP2L1 coding region showing conserved N-terminal

(B) Genomic sequence of show target sgRNA1 region (yellow), sgRNA 2 (blue) and

(C) DNA gel (1.6\%) from PCR showing DNA ladder and a 1000bp product in scramble sgRNA and reduced band in BAIAP2L1 sgRNA using primer 2 region for

(D) Lactate dehydrogenase (LDH) assay showing absorbance at $490 \mathrm{~nm}$ in supernatants from sgRNA transfected cells treated with media alone, TNF- $\alpha$ or acetylcholine. Positive control are dead cells killed by $1 \%$ Triton $\mathrm{X}$ and control is 
Fig. S8.

A B
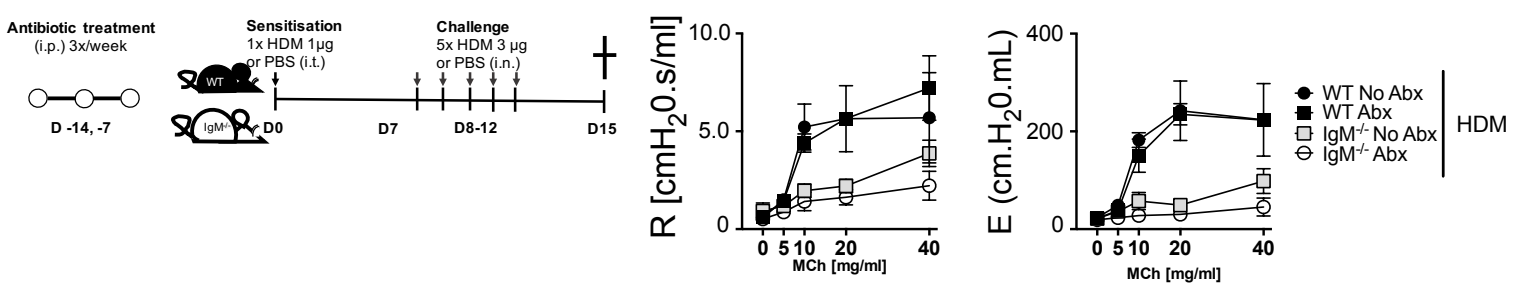

C
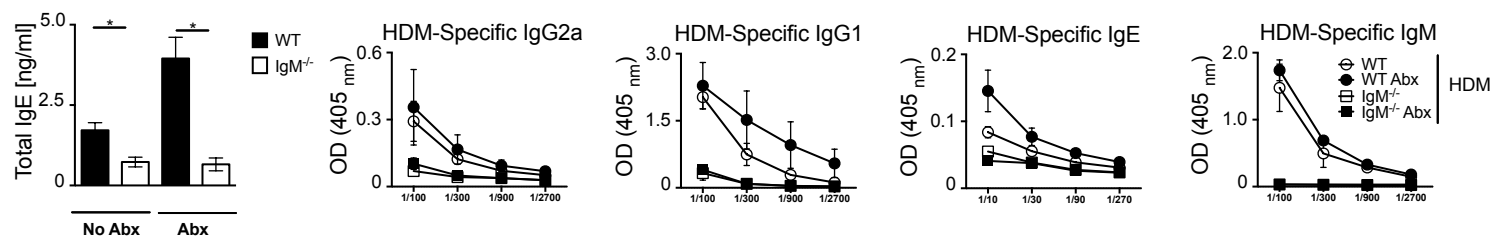

Reduced airway hyperresponsiveness in IgM-deficient mice is independent of microbial influence in HDM induced asthma.

751 (A) Schematic diagram showing treatment of $\operatorname{lgM}^{-/-}$and WT mice with antibiotic mixture 3 times a week for 2 weeks via oral gavage. These mice were then sensitised and challenged as in Fig. 1, A.

754

(B) Airway resistance and elastance were measured with increasing doses of acetyl

755 methacholine $(0-40 \mathrm{mg} / \mathrm{mL})$.

756

(C) Total IgE, HDM-specific IgG2a, HDM-specific IgG1, HDM-specific IgE and HDMspecific lgM in serum.

758 Shown is mean \pm SDs from 1 experiment $(n=4-6)$. Significant differences between

759 groups were performed by student t-test (Mann-Whitney) and are described as: ${ }^{*} p<0.05,{ }^{* *} p<0.01,{ }^{* * *} p<0.001,{ }^{* * * *} p<0.0001$. 